\title{
Reversible acute renal failure due to Churg-Strauss syndrome
}

\author{
A. Davenport, I. McDicken ${ }^{1}$ and H.J. Goldsmith \\ Liverpool Regional Renal Unit, ${ }^{1}$ University Department of Pathology, Royal Liverpool Hospital, Prescot \\ Street, Liverpool, UK.
}

\begin{abstract}
Summary: Renal disease in Churg-Strauss syndrome is generally thought to be benign in nature, thereby distinguishing this rare condition from other necrotizing vasculitides. We report a case in which acute renal failure developed during the aggressive vasculitic phase of the illness requiring dialysis therapy. After one week of daily haemodialysis treatment the patient had become encephalopathic associated with marked peripheral eosinophilia. Treatment with prednisolone resulted in a marked improvement in both clinical condition and renal function.
\end{abstract}

\section{Introduction}

Churg-Strauss syndrome (CSS) is a rare condition comprising hypereosinophilia, necrotizing vasculitis, eosinophilic tissue infiltration and extra-vascular granulomas, usually in patients with earlier allergic manifestations affecting the respiratory tract. ${ }^{1}$ Whereas both polyarteritis nodosa and Wegener's granulomatosis can present with acute renal failure, patients with Churg-Strauss syndrome usually have only mild to moderate renal impairment at most. In the Mayo Clinic series only 1 of 30 patients developed renal failure ${ }^{2}$ and in the series reported by the Hammersmith group, 1 patient of 16 developed renal failure but did not require dialysis treatment. ${ }^{3}$ We wish to report a case of acute renal failure due to CSS in a patient with diabetic nephropathy. His clinical course deteriorated with the introduction of haemodialysis treatment as he became encephalopathic with a marked hypereosinophilia. Treatment with high dose steroids produced a marked improvement.

\section{Case report}

A 37 year old Kenyan Asian businessman with juvenile onset diabetes mellitus had attended a renal clinic since 1981 when proteinuria had first been found. Background diabetic retinopathy and absent ankle jerks were noted. His renal function steadily

Correspondence: A. Davenport, M.A., M.R.C.P., Renal Unit, St James's University Hospital, Beckett Street, Leeds LS9 7TF, UK.

Accepted: 28 March 1988 declined and his proteinuria increased to $4 \mathrm{~g} / 24 \mathrm{~h}$. In 1984 he developed intrinsic asthma.

$\mathrm{He}$ was well on clinic review in February 1986 but had suffered with recurrent chest infections the previous winter. In April he was admitted as an emergency, complaining of general malaise with recent onset of swollen feet, nausea, vomiting and oliguria.

On examination he was distressed, with engorged jugular veins, sinus tachycardia, a blood pressure of $130 / 80 \mathrm{~mm} \mathrm{Hg}$ and an audible pericardial rub. Marked peripheral oedema and hepatomegaly were noted. The chest was clear. He had no new neurological signs. Two vasculitic skin lesions were present.

Initial investigations: haemoglobin $9.2 \mathrm{~g} / \mathrm{dl}$, leukocytes $19.3 \times 10^{9} / 1 ; 31.6 \%$ neutrophils, $51.8 \%$ eosinophils, erythrocyte sedimentation rate $34 \mathrm{~mm} / \mathrm{h}$. Serum values - urea $36.9 \mathrm{mmol} / \mathrm{l}$, creatinine $1019 \mu \mathrm{mol} / \mathrm{l}$, alkaline phosphatase $339 \mathrm{IU} / \mathrm{l}$, other liver function tests, albumin and globulin normal. Muscle enzymes were moderately elevated, creatine kinase 295IU/1 (normal <194), $3 \beta$-hydroxybutyrate dehydrogenase $290 \mathrm{IU} / 1$ (normal $<190$ ) and aldolase $9.2 \mathrm{IU} / 1$ (normal <7.6). Apart from a C-reactive protein of $99.2 \mathrm{mg} / \mathrm{l}$ (normal $<6$ ) and an $\mathrm{IgE}$ of $1,450 \mathrm{IU} / \mathrm{ml}$ (normal $<200$ ); all other serum immunological tests were normal. Urine stick testing revealed blood $3+$ and protein $3+$. Microscopy showed granular casts and red cells culture was negative.

Radiologically his cardiac silhouette was globular. He had shadowing at the right base and left mid zone. An electrocardiogram showed inverted T waves over the antero-lateral leads and a two 
dimensional echocardiogram confirmed the presence of a pericardial effusion. An ultrasound scan noted hepatomegaly and normal sized kidneys.

All blood cultures, viral titres and parasitological investigations were negative. Respiratory function tests confirmed an obstructive defect and bone marrow examination noted a hypercellular marrow with a predominance of mature eosinophils and their precursors. Renal biopsy showed an exudative diabetic glomerulopathy with fibrinoid caps which contained both IgM and $\mathrm{C}_{3}$ as did the intima of the arteries. In addition, there was a marked eosinophilic interstitial nephritis with granuloma formation (Figure 1).

Treatment was begun with daily haemodialysis using a cuprophan membrane. This was tolerated poorly, with coughing fits, bronchospasm, hypotension and pyrexia with rigors which developed soon after commencing dialysis. After a week of haemodialysis, during which the eosinophil count rose to $50,000 \times 10^{9} / 1$, the patient became drowsy and then increasingly encephalopathic. Peritoneal dialysis was substituted and pulsed methyl prednisolone commenced. He was transfused as the haemoglobin had fallen to $3.9 \mathrm{~g} / \mathrm{dl}$. Thirty-six hours later he was making a remarkable recovery, the pyrexia had resolved and the eosinophil count had fallen precipitously. Urine output increased and after a week peritoneal dialysis could be discontinued (Figure 2). Oral prednisolone was cautiously reduced from $60 \mathrm{mg} /$ day and he was discharged 4 weeks after admission. Six weeks later the serum creatinine was $450 \mu \mathrm{mol} / 1$, close to the pre-ChurgStrauss episode.

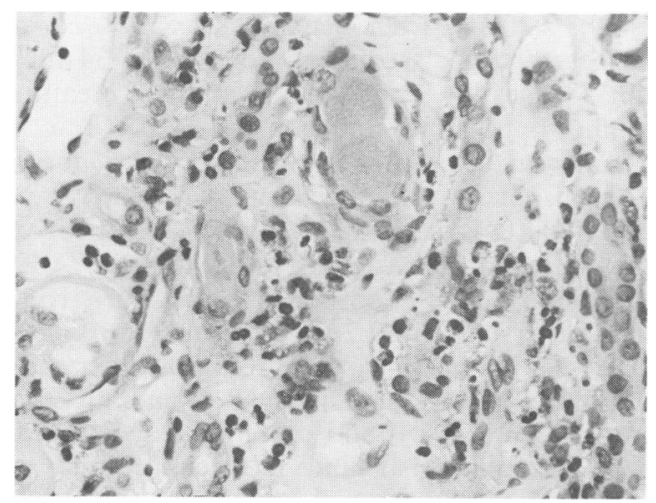

Figure 1 Light microscopical appearance of renal biopsy showing a marked interstitial nephritis with a predominance of eosinophils and granuloma formation.
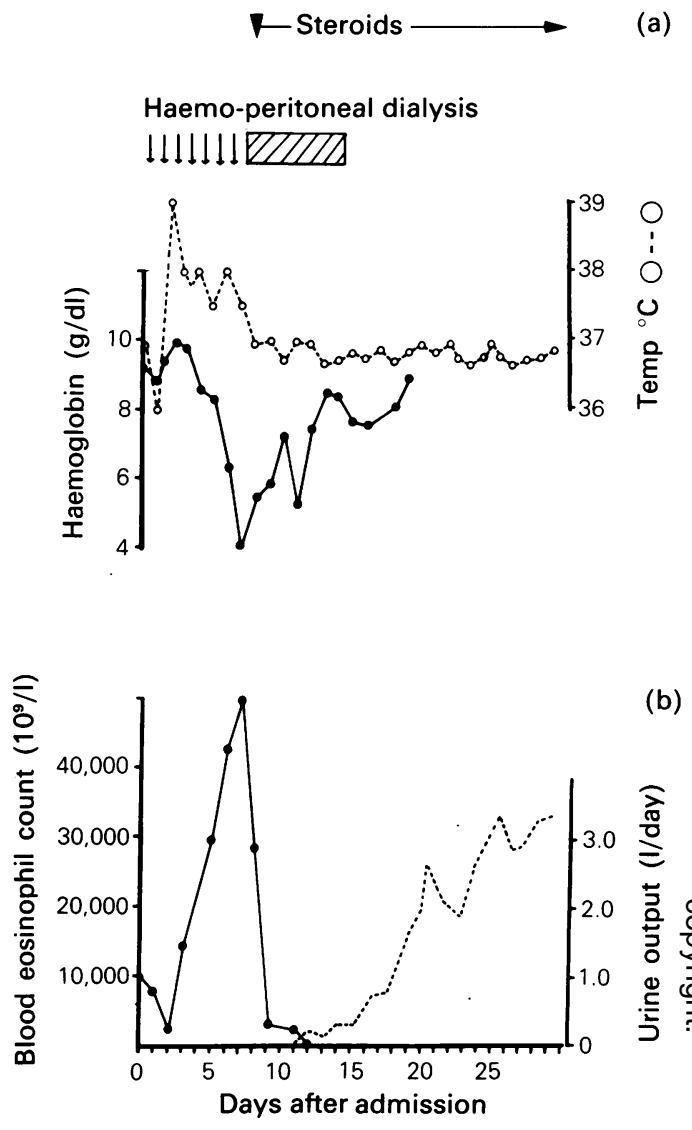

(b)

Figure 2 Patient's clinical course. (a) - Haemoglobin $(\mathrm{g} / \mathrm{dl})$; $\bigcirc--\bigcirc$, temperature $\left({ }^{\circ} \mathrm{C}\right)$. (b) $-\mathrm{O}$, Blood eosinophil count $\left(\times 10^{9} / 1\right) ;---$, urine output (1/day).

\section{Discussion}

This case of acute renal failure due to ChurgStrauss syndrome in an insulin-dependent diabetic acts as a reminder that not all cases of renal failure in diabetics are due to diabetic nephropathy.

Churg-Strauss syndrome is a subtype of polyarteritis nodosa and mainly affects the renal vasculature although eosinophilic granuloma as in this case may also be present. Medium arteries, arterioles or glomeruli can be involved in a focal necrotizing arteritis resulting in small areas of infarction. Acute lesions are seen with areas of fibrinoid necrosis and thrombosis with intense inflammatory cell infiltration. Lesions heal resulting in vascular scarring or in the glomeruli scars within the tufts. Interstitial nephritis may typically occur without histological evidence of glomerular involve- 
ment. The interstitium may also show intense eosinophilic infiltration with the formation of eosinophilic granulomata. ${ }^{4}$

This man had suffered with asthma for the 3 years in the prodromal phase of his illness without any record of blood or sputum eosinophilia, with negative skin tests. He then developed an aggressive vasculitic phase presenting in acute renal failure with pericarditis and lung involvement. ${ }^{5} \mathrm{He}$ then became encephalopathic with an eosinophil count of $50,000 \times 10^{9} / 1$, presumably a direct effect of the eosinophilia rather than a cerebral vasculitis. An eosinophil-derived neurotoxin has been described in cases of encephalopathy associated with the hypereosinophilia syndrome, although both major basic protein and eosinophilic cationic protein may also contribute to the neurological dysfunction. ${ }^{6}$ The rapid fall in haemoglobin has been noted previously in the active vasculitic phase. ${ }^{7}$

The substantial rise in the peripheral eosinophil count over the first week of daily haemodialysis treatment was more likely related to the bioincompatibility of the dialyzer membrane used rather than an increase in the underlying disease

\section{References}

1. Churg, J. \& Strauss, L. Allergic granulomatosis, allergic angiitis and peri arteritis nodosa. Am J Pathol 1951, 27: 277-301.

2. Chumbley, L.C., Harrison, G.P. \& DeRemee, R.A. Allergic granulomatosis and angiitis Churg-Strauss syndrome. Mayo Clin Proc 1977, 52: 477.

3. Langham, J.C., Elkon, K.B., Pusey, C.D. \& Hughes, G.R. Systemic vasculitis with asthma and eosinophilia: a clinical approach to the Churg-Strauss syndrome. Medicine 1985, 63: 65-81.

4. Strauss \& Welt (eds). Diseases of the Kidney, Vol. 2. Little, Brown, Boston, 1979, pp 1270-1276. activity. The adverse reactions noted during haemodialysis reflect the degree of complement activation and eosinophil degranulation associated with the use of cuprophan dialysis membranes.

\section{Conclusions}

We have described a rare case of acute renal failure associated with the aggressive vasculitic phase of Churg-Strauss syndrome. The patient required dialysis therapy for management of his acute renal failure and we believe that the use of a cuprophan dialyzer caused the activation of peripheral eosinophils resulting in the development of encephalopathy. Fortunately his condition responded to treatment with prednisolone.

In future we would recommend the use of either peritoneal dialysis or haemofiltration with a more bio-compatible membrane for the treatment of patients with acute renal failure due to CSS until renal function improves under the influence of steroids and immunosuppressants.

5. Jolobe, O.M.P. \& Melnick, S.C. Asthma, pulmonary eosinophilia and eosinophilic pericarditis. Thorax 1983, 38: 690-691.

6. Moore, P.M., Harley, J.B. \& Fauci, A.S. Neurological dysfunction in the ideopathic hypereosinophilic syndrome. Clin Exp Neurol 1983, 19: 60-66.

7. Langham, J.G., Cooke, S., Davies, J. \& Hughes, G.R. Endomyocardial complications of the Churg-Strauss syndrome. Postgrad Med J 1985, 61: 341-344. 